\title{
Algoritma Dynamic Cluster Head dengan Metode Rating untuk Mengurangi Dead Node pada Jaringan Sensor Nirkabel
}

\author{
I Gusti Ngurah Ady Kusuma \\ Program Studi Sistem Komputer, STMIK - STIKOM Bali \\ Jalan Raya Puputan No.86 Renon Denpasar -Bali, Telp. 0361-244445 \\ e-mail: ady_kusuma@stikom-bali.ac.id
}

\begin{abstract}
Abstrak
Jaringan sensor nirkabel terdiri dari node-node sensor yang memiliki sumber daya energi yang terbatas. Jaringan ini dibangun untuk mengawasi lingkungan dan memberikan informasi ke sebuah koordinator. Namun karena node yang berjalan dengan sumber daya terbatas seperti baterai, diperlukan sebuah protokol yang mampu memanfaatkan sumber daya yang terbatas namun data yang disampaikan tetap terjaga. In-network data aggregation merupakan sebuah metode agregasi pengumpulan data routing melalui jaringan multi-hop, mengolah data pada intermediate node dengan tujuan meningkatkan network lifetime. Agregasi data dilakukan secara terpusat pada topologi Tree-Based Network yang diproses pada Cluster Head sehingga memberikan beban pada Cluster Head yang mengakibatkan konsumsi energi terpusat pada satu node. Penelitian ini menghasilkan algoritma penentuan node yang bertugas menjadi Cluster Head sesuai dengan kondisi jaringan secara dinamis yang disebut A-SEClush. Berdasarkan hasil uji coba yang telah dilakukan algoritma ini memiliki keunggulan sebesar 2,0 pada total node yang mengalami kehabisan energi dibandingkan dengan Static-CH.
\end{abstract}

Kata kunci: Wireless Sensor Network, Data Aggregation, Dynamic Cluster Head, Energy Efficiency, Rating Mechanism.

\begin{abstract}
Wireless sensor networks consist of sensor nodes that have limited power. This network was built to oversee the environment and provide information to a coordinator. However, because the nodes running with limited resources such as batteries, a protocol is needed that is able to utilize limited resources but the data delivered is maintained. In-network data aggregation is an aggregation method of collecting routing data through multi-hop networks, processing data at intermediate nodes with the aim of increasing network lifetime. Data aggregation is carried out centrally on the Tree-Based Network topology which is processed in the Cluster Head so as to provide a load on the Cluster Head which results in centralized energy consumption. This study produces an algorithm to determine the nodes in charge of Cluster Head according to a dynamic network condition called A-SEClush. Based on the results of trials that have been carried out this algorithm has an advantage of 2.0 on the total nodes that experience run out of energy compared to Static- $\mathrm{CH}$.
\end{abstract}

Keywords: Wireless Sensor Network, Data Aggregation, Dynamic Cluster Head, Energy Efficiency, Energy Rating.

\section{Pendahuluan}

Komunikasi nirkabel merupakan komunikasi yang terjadi antara 2 sisi yaitu pemancar dan penerima atau transmitter dan receiver [1]. Pemancar (transmitter) bertugas untuk mengirimkan data yang selanjutnya akan diterima oleh penerima (receiver). Pada komunikasi nirkabel ada banyak perangkat yang digunakan, namun secara umum terdapat 2 jenis perangkat yaitu perangkat lapangan atau field device dan perangkat infrastruktur.

Jaringan sensor nirkabel merupakan salah satu pengembangan dari komunikasi nirkabel yang diaplikasikan dalam perangkat yang berukuran kecil, ringan dan memiliki skalabilitas biaya jaringan yang rendah [2]. Jaringan sensor nirkabel dibekali dengan seperangkat sumber daya energi yang terbatas yang digunakan dalam operasi komputasi dan memiliki kemampuan untuk melakukan sensing dan komunikasi nirkabel [3]. Perangkat yang tergabung dalam jaringan sensor nirkabel memiliki tujuan dengan spesifikasi

p-ISSN: 2089-1814; e-ISSN: 2460-3694; DOI: 10.30864/eksplora.v8i2.218 
yang sama. Sebagai contoh digunakan dalam berbagai skenario industri, bidang kesehatan, bahkan sebagai alat deteksi dini ledakan [4].

Perangkat jaringan sensor nirkabel, meskipun dengan terbatasnya sumber energi, perangkat tetap dituntut memiliki network lifetime yang panjang. Network lifetime merupakan durasi waktu sebelum beberapa perangkat dalam jaringan tersebut mati [5]. Hal ini memerlukan sebuah efisiensi dalam algoritma operasional dari sistem jaringan. Terutama pada bagian pengiriman dan penerimaan data. Ketika melakukan transmisi, perangkat mengonsumsi energi lebih banyak.

Pengurangan jumlah data yang dikirimkan pada jaringan sensor nirkabel telah diteliti sebelumnya dengan metode agregasi data [6]. Pada metode ini, semua data dikumpulkan dalam suatu node kemudian diproses dan digabungkan yang menghasilkan satu data baru yang mewakili semua data yang telah dikumpulkan. Metode ini bertujuan untuk melakukan efisiensi pengiriman dan berhasil melakukan efisiensi pada energi yang digunakan ketikan melakukan transmisi.

Pada sebuah jaringan komputer yang luas muncul sebuah konsep pengembangan dari agregasi data yaitu menjadi in-network data aggregation. Aplikasi dari metode ini adalah dengan mengumpulkan semua data pada router kemudian mengirimkan data tersebut ke node selanjutnya. Router atau titik berkumpulnya data tersebut disebut dengan intermediate node [7]. Terdapat 2 jenis in-network data aggregation yaitu dengan melakukan kombinasi dan kompresi pada data yang dikumpulkan dan menghasilkan 1 data baru yang disebut dengan with size reduction. Kemudian cara yang kedua adalah dengan without size reduction di mana semua data dikumpulkan dan digabungkan tanpa adanya kompresi atau penghilangan beberapa informasi dari data tersebut.

Metode agregasi data pada sebuah jaringan sensor nirkabel ini sering diaplikasikan dengan memodelkan jaringan dalam bentuk cluster dan masing-masing cluster memiliki cluster head yang berfungsi sebagai intermediate node. Sebagai salah satu contoh pada penelitian [8] dan [9] di mana agregasi dilakukan pada sebuah cluster head.

Muncul permasalahan di mana ketika jaringan sudah beroperasi, cluster head yang dipilih bersifat fixed atau tetap dan hal tersebut mengakibatkan kecenderungan penggunaan energi yang lebih banyak dibebankan pada cluster head. Hal ini memiliki risiko yang tinggi, karena ketika cluster head mengalami kehabisan energi maka node yang berada di bawah cluster head tersebut akan terisolir. Semakin banyak cluster yang terisolir maka semakin berkurang sensitivitas pengawasan pada wilayah tersebut. Hal ini akan berdampak buruk pada situasi pemantauan wilayah karena turunnya sensitivitas mengakibatkan tingginya persentase kegagalan dalam melakukan deteksi dini pada sebuah wilayah.

Berdasarkan hal tersebut, penulis melakukan penelitian untuk meneliti algoritma dalam pemilihan cluster head secara dinamis. Penelitian ini menggunakan sistem rating untuk melakukan penilaian pada masing-masing untuk menentukan cluster head. Penilaian atau rating akan dilakukan secara periodik sehingga cluster head akan dipilih secara periodik. Pemilihan cluster head secara dinamis berarti melakukan pemerataan konsumsi energi pada setiap node sehingga dapat memperpanjang umur jaringan hingga sampai salah satu mengalami kehabisan energi.

\section{Metode Penelitian}

Wireless sensor network (WSN) atau jaringan sensor nirkabel merupakan sekumpulan dari beberapa device kecil yang dilengkapi dengan sensing yang terintegrasi dan kemampuan komunikasi nirkabel, yang diharapkan dapat digunakan secara luas dalam berbagai aplikasi. Sensor ini dioperasikan dengan daya baterai dan energinya tidak selalu diperbaharui karena masalah biaya, lingkungan dan bentuknya [2].

Umumnya nodes dalam jaringan tersebut memiliki tujuan yang sama seperti pemantauan lingkungan atau deteksi kejadian. WSN digunakan untuk monitoring area yang tidak dapat dicapai seperti gletser, kebakaran hutan, gurun, dan kedalaman lautan. Energi dalam WSN nodes digunakan pada CPU, sensor, dan radio yang di mana merupakan mengonsumsi energi terbanyak. Untuk mengoptimalkan penggunaan energi, identifikasi source yang paling besar menghabiskan energi dalam komunikasi sangatlah penting, seperti collision, overhearing, control packet overhead, dan idle listening. Salah satu tantangan untuk mencapai teknologi potensial ini yaitu dengan manajemen konsumsi energi yang efektif dalam node device ini untuk memaksimalkan lifespan sebuah dan akhirnya lifespan jaringan pada saat yang sama juga cukup memelihara kualitas dan kuantitas service [4]. node sensor umumnya dilengkapi dengan tranceiver radio, pengontrol mikro, unit memori, dan penggunaan satu set transduser yang dapat memperoleh dan mengolah data sehingga dapat mengorganisir sendiri untuk membentuk jaringan multi-hop dan mengirimkan data ke sink [10].

Data-Aggregation merupakan sebuah penggabungan dari kumpulan atau himpunan data yang diproses sehingga menghasilkan data yang baru. Pada jaringan sensor nirkabel Data-Aggregation

Algoritma Dynamic Cluster Head dengan Metode Rating untuk Mengurangi Dead Node pada Jaringan Sensor Nirkabel (I Gusti Ngurah Ady Kusuma) 
didefinisikan sebagai penggabungan data dari beberapa sensor untuk menghilangkan transmisi yang berlebihan dan memberikan kesatuan informasi ke koordinator sensor [7]. Agregasi data biasanya melibatkan fusion data dari beberapa sensor di intermediate node dan proses transmisi dari data tersebut menuju koordinator.

Agregasi data merupakan upaya untuk mengumpulkan data yang paling penting dari sensor dan membuat data tersebut diterima oleh koordinator dengan tetap memperhatikan efisiensi energi. Latency dari sebuah data juga sangat penting dalam banyak aplikasi seperti aplikasi pada pemantauan keadaan lingkungan di mana data terbaru merupakan faktor penting. Hal yang terpenting dari data agregasi adalah pengembangan algoritma yang mampu menambah network lifetime dari sebuah jaringan sensor nirkabel. Ada beberapa faktor yang mempengaruhi efisiensi dari penggunaan energi pada jaringan sensor nirkabel dengan agregasi data seperti arsitektur jaringan, mekanisme agregasi data, dan protokol pengiriman.

Agregasi dilakukan pada sebuah intermediate yang bertindak sebagai cluster head. Semua data yang berasal dari semua pada cluster tersebut akan dikumpulkan pada cluster head. Masing-masing menentukan sebuah cluster head secara permanen, yang berarti ketika sebuah telah memilih cluster head maka cluster head akan bersifat permanen dan tidak dapat diubah. Hal ini akan membuat energi pada cluster head akan lebih cepat habis dibandingkan dengan yang lain. Berdasarkan hal tersebut, pada penelitian ini lebih berpatokan pada energi yang tersisa pada sebuah untuk memilih sebuah cluster head. Sehingga ketika sebuah cluster head yang dipilih sebelumnya mengalami kehabisan atau kondisi energinya lebih rendah maka akan memilih cluster head dengan tingkat energi yang lebih tinggi.

Selain energi, terdapat beberapa indikator yang digunakan sebagai metode perhitungan rating dari sebuah node yaitu sink distance dan neighbors count. Sink distance digunakan sebagai indikator untuk menghindari pemilihan cluster head yang jauh dari sink atau pusat. Asumsinya adalah ketika memilih cluster head yang jauh dari sink akan memperlambat pengiriman data. Kemudian neighbors count juga menjadi acuan rating dengan asumsi semakin banyak tetangga yang dimiliki oleh cluster head, maka semakin banyak jalur pilihan yang dimiliki untuk menuju sink.

Pada penelitian ini dilakukan sebuah perancangan untuk merancang alur dasar dari algoritma yang akan diteliti. Penelitian ini menggunakan sistem rating atau penilaian sehingga nantinya setiap node akan memiliki nilai-nilai yang didapatkan dari perhitungan beberapa variabel. Tabel 1 merupakan indicator penilaian beserta bobot penilaian dari algoritma ini.

Tabel 1. Bobot penentuan cluster head.

\begin{tabular}{cc}
\hline Indikator & Bobot (\%) \\
\hline Energy Level (EL) & 50 \\
\hline Sink Distance (SD) & 30 \\
\hline Neighbors Count (NC) & 20 \\
\hline
\end{tabular}

Faktor energy level menggambarkan sisa energy yang tersisa pada sebuah node. Sink distance merupakan jarak antara node tersebut dengan sink node. Sedangkan neighbors count merupakan jumlah tetangga node aktif yang dimiliki oleh node tersebut.

Masing-masing node akan melakukan perhitungan penilaian untuk masing-masing node sehingga masing-masing node akan memiliki nilai yang kemudian dibandingkan dengan node yang lain. node yang memiliki nilai tertinggi nantinya akan dipilih sebagai cluster head. Gambar 1 merupakan diagram alir dari penentuan cluster head. Pada Gambar 1 dilakukan penilaian terhadap setiap yang bertetangga, dimulai dari salah satu tetangga. node akan dibandingkan dengan kondisi rata-rata energi yang tersedia pada cluster tersebut. Jika energi yang dimiliki oleh calon cluster head tersebut lebih tinggi dari tingkat energi rata-rata pada cluster tersebut baru selanjutnya akan dilakukan proses rating atau penilaian dengan melibatkan indikator pada Tabel 1. Hal tersebut terus dilakukan secara berulang pada keseluruhan tetangga sehingga memastikan bahwa yang dipilih sebagai cluster head memiliki energi di atas rata-rata dengan penilaian yang paling tinggi. Proses penentuan cluster head dilakukan secara periodik oleh setiap. Proses penentuan ini ditentukan secara konstan setiap 1800 detik. Pada proses penentuan, akan mencari nilai rating tertinggi dengan energi yang nilainya di atas rata-rata. 


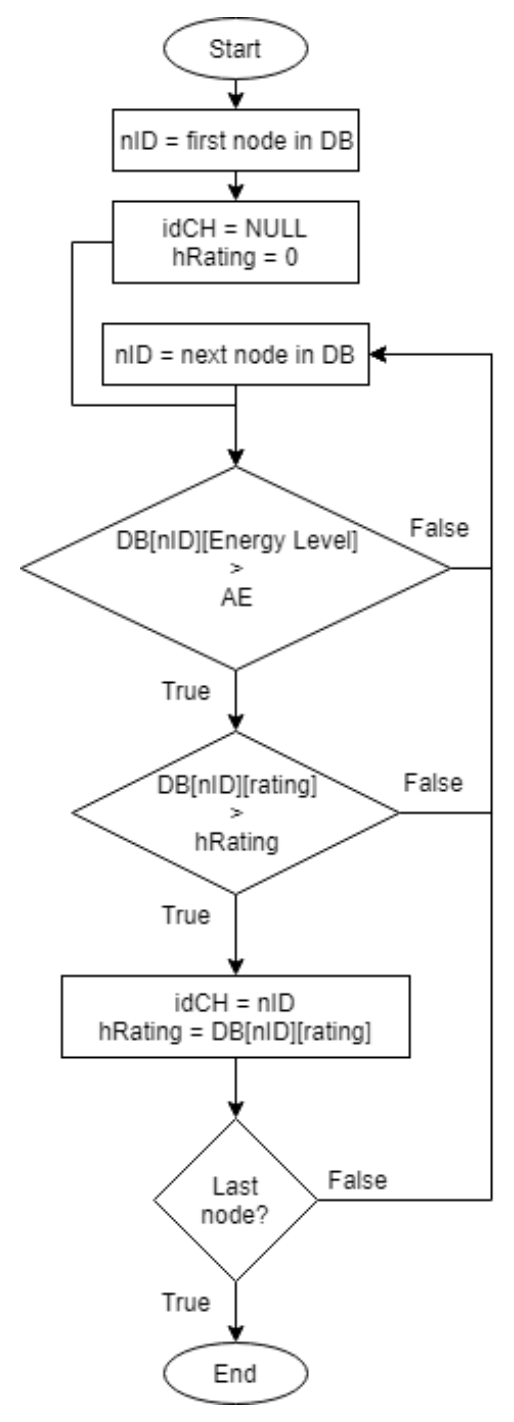

Gambar 1. Diagram alir proses pemilihan cluster head.

Protokol yang diteliti ini diujikan dengan menggunakan simulator jaringan sensor nirkabel SIDnet-SWANS. SIDnet-SWANS telah menyediakan salah satu protokol routing berbasis lokasi yaitu Shortest Geo Path Routing Protocol dan protokol routing Hearthbeat Protocol untuk melakukan discovery terhadap tetangga. Penelitian yang dilakukan ini adalah melakukan modifikasi pada protokol routing Shortest Geo Path dalam penanganan pengiriman nilai data pengamatan sensor dengan menggunakan konsep tree-based aggregated routing. Modul protokol routing SGP pada SIDnet-SWANS akan dikembangkan agar dapat mengimplementasikan protokol Aggregated Shortest Geo-Path Routing with Adaptive Payload, menambahkan modul baru untuk menangani adaptive payload, dan melakukan modifikasi pada modul 802.15 untuk menangani laporan pengiriman data.

\section{Hasil dan Pembahasan}

Pengujian algoritma dilakukan dengan memanfaatkan simulator sebagai wadah untuk melihat efektivitas dalam penerapannya. Simulator yang digunakan yakni adalah SIDNet-SWANS. Algoritma yang diujikan diberikan kode A-SEClush dan yang tanpa algoritma yang diusulkan dikodekan sebagai Static$\mathrm{CH}$. Gambar 2 merupakan tampilan di mana simulator sedang berjalan. Pada gambar tersebut, terlihat bagaimana algoritma menghasilkan beberapa garis pola penentuan cluster head (berwarna merah). Pada gambar tersebut pula, simulasi terus dilanjutkan hingga semua kehabisan energi. node yang kehabisan energi kemudian dikategorikan sebagai dead node atau node mati. 


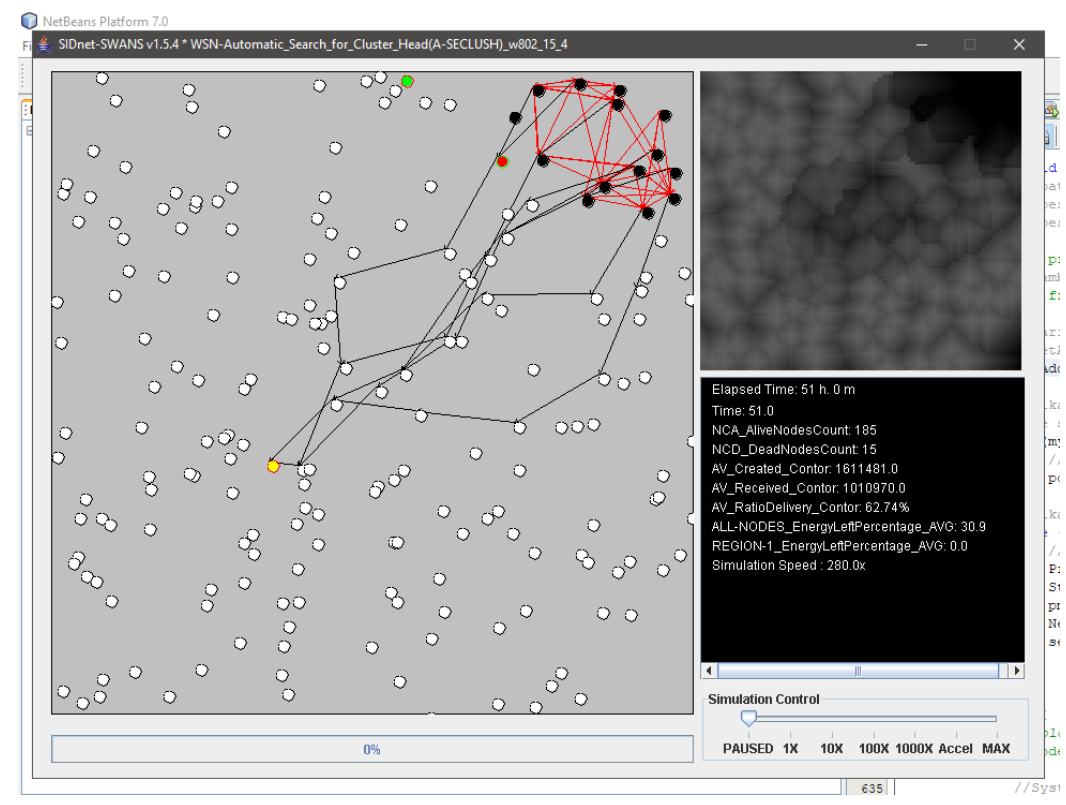

Gambar 2. Tampilan uji coba algoritma.

Pengujian yang dilakukan kemudian dibandingkan dengan pengiriman yang tanpa melibatkan pemilihan cluster head secara dinamis (Static-CH). Pengujian dilakukan sebanyak 3 kali di mana dalam satu kali pengujian dijalankan simulasi selama 48 jam waktu simulator dan pengambilan data lingkungan atau sampling dilakukan setiap satu detik. Tabel 2 merupakan rangkuman hasil uji coba yang dilakukan terhadap algoritma tersebut.

Tabel 2. Hasil uji coba algoritma terhadap total dead node.

\begin{tabular}{ccc}
\hline Percobaan ke: & A-SEClush & Static-CH \\
\hline 1 & 12 & 13 \\
\hline 2 & 13 & 15 \\
\hline 3 & 12 & 15 \\
\hline Rata-rata & 12,33 & 14,33 \\
\hline
\end{tabular}

Berdasarkan Tabel 2, A-SEClush memiliki rata-rata total dead node 12,33 yang lebih rendah dibandingkan Static-CH yaitu 14,33. Meskipun hanya unggul 2,0, A-SEClush terbukti mampu memberikan network lifetime yang lebih panjang sehingga jumlah yang kehabisan energi menjadi lebih rendah dari Static-CH. Sekali lagi dengan pemilihan cluster head yang dinamis, dapat meratakan konsumsi energi pada seluruh node karena proses agregasi tidak hanya terjadi pada satu. Tabel 3 merupakan rangkuman dari hasil pengamatan pada Total Dead node yang diamati tiap jam setelah terdapat 1 dead node .

Tabel 3. Hasil Pengamatan Total Dead node.

\begin{tabular}{cccc}
\hline Waktu & \multicolumn{3}{c}{ Total Dead Node pada Percobaan ke: } \\
\cline { 2 - 4 }$\left(\begin{array}{l}\text { Jam }) \\
\mathbf{2 5}\end{array}\right.$ & $\mathbf{1}$ & $\mathbf{2}$ & $\mathbf{3}$ \\
\hline $\mathbf{2 6}$ & 0 & 1 & 0 \\
\hline $\mathbf{2 7}$ & 0 & 1 & 1 \\
\hline $\mathbf{2 8}$ & 1 & 2 & 1 \\
\hline $\mathbf{2 9}$ & 2 & 2 & 2 \\
\hline $\mathbf{3 0}$ & 3 & 4 & 2 \\
\hline $\mathbf{3 1}$ & 5 & 4 & 4 \\
\hline $\mathbf{3 2}$ & 5 & 4 & 4 \\
\hline $\mathbf{3 3}$ & 5 & 6 & 6 \\
\hline $\mathbf{3 4}$ & 6 & 6 & 6 \\
\hline $\mathbf{3 5}$ & 6 & 6 & 6 \\
\hline $\mathbf{3 6}$ & 6 & 6 & 6 \\
\hline $\mathbf{3 7}$ & 6 & 6 & 6 \\
\hline $\mathbf{3 8}$ & 6 & 7 & 6 \\
\hline $\mathbf{3 9}$ & 6 & 7 & 7 \\
\hline & 8 & 7 & 7 \\
\hline
\end{tabular}




\begin{tabular}{cccc}
\hline $\mathbf{4 0}$ & 9 & 8 & 8 \\
\hline $\mathbf{4 1}$ & 9 & 8 & 9 \\
\hline $\mathbf{4 2}$ & 9 & 9 & 10 \\
\hline $\mathbf{4 3}$ & 11 & 12 & 11 \\
\hline $\mathbf{4 4}$ & 12 & 13 & 12 \\
\hline
\end{tabular}

Berdasarkan data dari Tabel 3 terlihat bahwa node mengalami kehabisan energy dimulai dari jam ke-25 di mana pada percobaan kedua terdapat 1 node yang mengalami kehabisan energi dan dikategorikan sebagai dead node. Pada jam ke-33 hingga ke-36 tidak ditemukan node yang mengalami kehabisan energi. Pada jam tersebut masih tersisa 9 dari 15 node yang masih aktif bekerja sehingga penyebaran cluster head yang dipilih masih merata. Dimulai dari jam ke-38 mulai ditemukan tingginya pertambahan jumlah node yang mengalami kehabisan energi. Hal ini disebabkan karena kondisi dari seluruh node yang sudah memiliki tingkat energy left di bawah 50\%. Selain itu jumlah node yang tersisa juga sudah di bawah ratio $50 \%$ yang mengakibatkan sedikitnya jumlah node yang dapat dipilih menjadi cluster head. Kondisi tersebut menyebabkan jumlah cluster head semakin sedikit dan konsumsi energi lebih terfokus pada satu node saja dan hal ini mengakibatkan cluster head tidak menyebar secara merata. Gambar 3 merupakan grafik Total Dead node yang diamati.

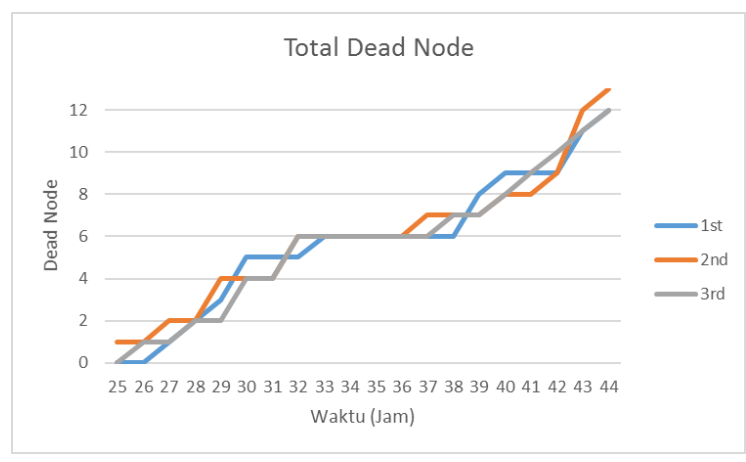

Gambar 3. Grafik total dead node yang diamati setiap jam.

\section{Kesimpulan}

Algoritma A-SEClush yang telah dirancang dan diimplementasikan ini memiliki keunggulan dari segi total dead node lebih sedikit 2 dibandingkan dengan Static- $\mathrm{CH}$. Hal ini disebabkan karena pemilihan cluster head yang dinamis sehingga cluster head tidak hanya terfokus pada satu melainkan tersebar secara merata dan bergiliran. Pemerataan penentuan cluster head ini pula dapat membantu pemerataan penggunaan energi pada proses agregasi untuk pengiriman data. Karena proses agregasi data tidak hanya terjadi pada salah satu saja, melainkan semua node berpotensi untuk menjadi cluster head. Hal ini dimungkinkan karena algoritma yang dirancang mampu memberikan penilaian berdasarkan kondisi dari energi, jarak dengan sink node dan jumlah tetangga yang dimiliki oleh setiap. Setelah diberikan penilaian selanjutnya dipilih terbaik yang memiliki nilai tertinggi yang akan dijadikan sebagai cluster head. Berdasarkan hasil pengujian terdapat beberapa saran yang bisa dikembangkan pada algoritma A-SEClush yang telah diujikan adalah perlunya peningkatan performa pada pengaturan antrean pengiriman data pada masing-masing node dengan optimalisasi pada sistem antrean pengiriman

\section{Daftar Pustaka}

[1] B. Mehta and Y. J. Reddy, "Wireless communication," in Industrial Process Automation Systems , Oxford, Elsevier's Science \& Technology, 2015, pp. 417-457.

[2] R. S. Carbajo, E. S. Carbajo, B. Basu and C. Mc Goldrick, "Routing in wireless sensor networks for wind turbine monitoring," Pervasive and Mobile Computing, vol. 39, pp. 1-35, 2017.

[3] M. Elshrkawey, S. M. Elsherif and M. Elsayed Wahed, "An Enhancement Approach for Reducing the Energy Consumption in Wireless Sensor Networks," Journal of King Saud University - Computer and Information Sciences, vol. 30, no. 2, pp. 259-267, 2018.

[4] A. J. AL-Mousawi and H. K. AL-Hassani, "A survey in wireless sensor network for explosives detection," Computers \& Electrical Engineering, vol. 39, pp. 1-35, 2017. 
[5] M. R. and R. Datta, "A novel source location privacy preservation technique to achieve enhanced privacy and network lifetime in WSNs," Pervasive and Mobile Computing, vol. 44, pp. 58-73, 2018.

[6] P. Padmaja and G. Marutheswar, "Energy efficient data aggregation in wireless sensor networks," Telangana, India, 2018.

[7] C. Li, J. Bai, J. Gu, X. Yan and Y. Luo, "Clustering routing based on mixed integer programming for heterogeneous wireless sensor networks," Ad Hoc Networks, vol. 72, pp. 81-90, 2018.

[8] I. G. N. A. Kusuma and W. Wibisono, "Adaptive Data Aggregation for Shortest Geopath Routing Protocol in Wireless Sensor Network," IPTEK, The Journal for Technology and Science, vol. 28, no. 2, pp. 51-54, 2017.

[9] W. Wibisono, I. G. N. Ady Kusuma, Y. Ishida and I. Winarmo, "Towards an Immunity-Based Approach for Preserving Energy of Data-Gathering Processes in Wireless Sensor Network Environments," in The 2016 International Conference on Advanced Informatics: Concepts, Theory and Application (ICAICTA2016), Penang, 2016.

[10] R. R. Rout and S. Gosh, "Enhancement of Lifetime using Duty Cycle and Network Coding in Wireless Sensor Networks," in IEEE Transactions on Wireless Communications, 2013. 